Fecha de recepción: abril 2020

Fecha de aceptación: mayo 2020

Versión final: junio 2020

\section{Arte mestiça de Jarbas Lopes e Marcos Cardoso: inventariantes das ruas $(1990-2010)$}

Gianne Maria Montedônio Chagastelles ${ }^{(1)}$

Resumo: $\mathrm{O}$ artigo trata da arte mestiça criada pelos artistas brasileiros contemporâneos Jarbas Lopes e Marcos Cardoso, entre os anos 1990 e 2010. Nessas obras eles apresentam culturas híbridas, rompendo com a diferença hierárquica entre artesanato e arte, indo ao encontro das noções de arte mestiça, especialmente a partir do conceito formulado por Néstor García Canclini. Discute-se o ambiente da arte e de existência do homem em seu cotidiano e as formas de controle do espaço e do corpo do sujeito, bem como as estratégias de resistência através da busca do rompimento de fronteiras entre erudito e popular.

Palavras chave: Arte mestiça - Culturas híbridas - Arte contemporânea brasileira - Jarbas Lopes - Marcos Cardoso.

[Resumos em espanhol e inglês nas páginas 90-91]

(1) Doutora em História Social pelo Programa de Pós-Graduação em História Social (PPGHIS) do Instituto de História (IH) da Universidade Federal do Rio de Janeiro (UFRJ). Professora Adjunta de História da Arte e Artes Visuais da Universidade do Estado do Rio de Janeiro (UERJ). Autora das seguintes obras: Alegoria na arte brasileira (19802000). Rio de Janeiro: Multifoco, 2013; e Eternidade do efêmero: memória e vivência na arte brasileira dos anos 90 - Jarbas Lopes, Laura Lima e Cabelo. Rio de Janeiro: Multifoco, 2012. Organizadora dos livros Ensaios de imagens: cidades. Rio de Janeiro: Multifoco, 2016; Ensaios de imagens: comunicação. Rio de Janeiro: Multifoco, 2017; Ensaios de imagens: deslocamentos. Rio de Janeiro: Multifoco, 2018.

Este artigo vai analisar como as obras de Jarbas Lopes e Marcos Cardoso se relacionam com as noções de arte mestiça, especialmente a partir do conceito de hibridação cultural formulado por Néstor García Canclini (2011), referindo-se a processos interétnicos e de descolonização que cruzam fronteiras. A partir desse conceito, propõe ainda a contextualização das obras mestiças na história da arte do Brasil. O diálogo entre popular e erudito está no âmago da discussão das obras de Jarbas Lopes e Marcos Cardoso que rompem com a visão de que o popular seria os excluídos, as minorias étnicas, rurais, subalternos, os ar- 
tesãos, ligados à tradição; e que o erudito seria o grupo hegemônico, dominante, do poder, ligado à história da arte oficial, à modernidade. Esses artistasem suas análises da arte erudita e da popular solapam com a pretensão de autonomia, pois tanto uma quanto a outra são constituídas por processos híbridos e complexos, impuros. Elesderrubam qualquer juízo binário em relação à cultura tais como erudito e popular, urbano e rural, moderno e tradicional. Para eles hibridação são processos socioculturais nos quais estruturas ou práticas que existem de forma separadas, se combinam para gerar novas estruturas e práticas. Desta forma, como analisar as manifestações artísticas que não cabem no erudito ou no popular, que brotam de seus cruzamentos ou em suas margens? É possível construir uma nova perspectiva de análise do tradicional-popular levando em conta suas interações com a cultura de elite. Neste contexto, desenvolvo a análise de obras de artistas como Jarbas Lopes e Marcos Cardoso que deslocam a fronteira entre popular e erudito dentro de um processo híbrido, mestiço, intercultural, que trabalha com as divergências. Esta hibridação sucede, por um lado, com artistas considerados "eruditos" que se apropriam dos elementos populares em suas obras e, por outro, com artistas ditos "populares" que entram no circuito das artes ditas "eruditas".

A obra de Jarbas Lopes e de Marcos Cardoso encontra referências na história da arte brasileira no que diz respeito ao conceito de arte mestiça. Retalhos de imagens soltas que aparecem como um convite a formarem um possível tecido cheio de tramas que se entrelaçam e soltam-se sem a necessidade de um fim, isto é, de uma rigorosa classificação. Encaixaremos aqui, para situar no tempo, obras do período colonial, como por exemplo, a Escultura Missioneira, a obra de Aleijadinho, Mestre Valentim e Mestre Ataíde; do modernismo brasileiro, a obra de Tarsila do Amaral entre outros; da arte contemporânea, a obra de Hélio Oiticica e Arthur Bispo do Rosário que podem constituir, segundo o trabalho em questão, mais tramas desse tecido.

\section{Para situar no tempo}

No Brasil, o diálogo entre arte erudita e popular, se manifesta de várias formas artísticas. No período colonial, nos séculos XVII e XVIII, há uma forte conexão entre a mão afrobrasileira, a mão indígena e a mão portuguesa na arte e arquitetura. A escultura Missioneira do Rio Grande do Sul é uma expressão híbrida entre a arte europeia e a indígena, dos guaranis. A imagem de Nossa Senhora da Conceição, do acervo do Museu Júlio de Castilhos é exemplar dessa mestiçagem entre a cultura erudita e a mão indígena brasileira. Esta imagem apresenta traços indígenas na face e nos cabelos longos e lisos, assinalando a emergência de valores plásticos e simbólicos da própria cultura guarani.

Segundo Emanoel Araújo (2010), a infiltração do elemento escravo nas artes brasileiras coincide com a própria eclosão das mesmas no Brasil. Em relação à hibridação da afrobrasilidade à arte cristã, um modelo exemplar é a talha da Igreja Santa Efigênia, em Ouro Preto, construída no século XVIII. A talha apresenta elementos típicos da cultura religiosa africana como, por exemplo, búzios, chifres de carneiro e cabra, marcas de iniciação, constituindo um exemplo notável de afloramentos de elementos, princípios e formas afro- 
brasileiras dentro da cultura dominante cristã. Popular e erudito mesclam-se dando um aspecto popular à talha colonial.

Para Emanoel Araújo, os negros escravos foram se tornando brasileiros e em contrapartida, com os escravos, os senhores e a sociedade colonial se africanizaram. Ainda neste período, a arte católica também faz pensar na mão de obra afro-descendente que a produziu, especialmente em seus grandes nomes que despontaram no século XVIII como, Aleijadinho, Mestre Ataíde e Mestre Valentim. Estes mestres mestiços se serviram de convenções formais africanas, produzindo uma arte genuinamente brasileira, diferente da arte europeia dominante. Assim, rompendo com a imitação subserviente da arte europeia, cruzaram as barreiras entre o erudito e o popular.

Mestre Valentim introduz uma diversidade de tipos fisionômicos em querubins que variam do tipo europeu ao de traços francamente negróides, passando por diversos graus de mestiçagens. Introduziu temas da flora e fauna tropical nas esculturas dos chafarizes no Passeio Público. Mestre Ataíde traduziu na sua pintura um clima alegre e tropical com tons azuis e vermelhos além de pintar anjos mulatos com sorriso maroto e a Virgem mulata na arte cristã, rompendo com o ideal europeu do homem branco. Deve-se levar em conta que não existiam escolas de arte acadêmica no Brasil no século XVIII e muitos de nossos artistas aprendiam arquitetura e arte de "ouvido", como por exemplo, Aleijadinho aprendeu o ofício, entre outros, com seu pai, arquiteto português. Quase toda obra de Aleijadinho é de caráter religioso, já de Mestre Valentim, além da predominância religiosa, inserem-se algumas importantes de natureza civil e urbana, como o Passeio Público no Rio de Janeiro.

Aleijadinho criou um estilo próprio, originalidade no mundo rococó luso-brasileiro. Inventou um tipo de planta específica com torres cilíndricas na Igreja de São Francisco de Assis de Ouro Preto, utilizava decoração rococó em pedra sabão do lado externo da Igreja, o que era algo original. Para Myriam Ribeiro (2002), muitas de suas obras superam em qualidade a arte metropolitana. Mário de Andrade (1984) comenta que a obra de Aleijadinho não corresponde apenas ao gosto europeu, mas sua arte adquire uma graça mais sensual e encantadora, uma delicadeza tão suave, eminentemente, brasileiras. Ele diz que é a solução brasileira da Colônia. E ainda escreve que é o mestiço e é logicamente a independência.

Na segunda década do século XX, dá-se a renovação das artes brasileiras. Acentua-se a descoberta das raízes brasileiras que levará ao movimento modernista. Carlos Zilio (1982), lembra que o modernismo é uma reação contra o academicismo na arte, contra a imitação subserviente de valores europeus e a criação de uma arte puramente brasileira. A ideia de antropofagia foi incorporada pelos teóricos do movimento enfatizando uma proposta anticolonialista e mestiça: correto é apropriar-se da cultura do colonizador, das vanguardas europeias, digerindo-as, e criando uma arte de acordo com a nossa realidade, tradições e necessidades. Com as nossas etnias, as nossas cores. A antropofagia foi a recusa das identidades dadas a priori pelo colonizador. Oswaldo de Andrade, autor do Manifesto Antropofágico, transformou o bom selvagem de Rousseau num mal selvagem, que devora o europeu, capaz de assimilar o outro para dar um novo sentido à tradicional relação colonizador-colonizado.

Essas ideias modernistas, expressas especialmente na literatura e na obra de Tarsila do Amaral, operaram uma expressiva e construtiva liberação para as minorias e para o po- 
pular. Mulheres, índios e negros tornaram-se, daí em diante, sujeitos de seus próprios discursos na história da arte do Brasil, tendo o direito de apropriação, transformação e cruzamento de fronteiras. Roberto Conduru (2007) afirma queem vez de negativa, degeneradora, a miscigenação étnica tornou-se positiva. A atenção dada então à cultura popular incentivou os artistas a olharem de modo especial algumas práticas e figuras oriundas das culturas africanas e indígenas, assim como das festas e tradições populares, as integrando ao ideário artístico formador da nação brasileira.

Em relação à arte mestiça modernista brasileira, um exemplo é a obra "A Negra" de Tarsila do Amaral, que rompe com a representação estereotipada da mulher negra. O estereótipo mais forte era a identificação da mulher negra com uma sensualidade exótica. A figura trabalhada por Amaral quebrou estereótipos exatamente quando, na nossa história, nossa negritude estava em perigo. Os governantes brasileiros haviam intensificado a imigração europeia para "branquear" o país. A Negra de Tarsila, assemelhando-se a um antigo ídolo da fertilidade, é muito mais do que isso. É a celebração das nossas raízes negras. Um dos seios nutre a nossa cultura, e está caído de tanto dar de mamar para os filhos das brancas. O outro está escondido, sendo negado da mesma maneira como o poder político estava tentando esconder nossa negritude e maquiá-la aumentando artificialmente a população branca. A obra apropria-se formalmente da arte de Léger, mas contém sentido brasileiro. O brutalismo da figura rompe com a fragmentação cubista. O seio é o primeiro plano, os lábios indicam a negritude e os olhos em flecha exprimem mais tédio do que ódio. Paulo Sérgio Duarte (1998, p. 42) escreve "sentada no chão, a Gioconda brasileira não sorri. É um maravilhoso monstro brasileiro". A inovação formal no fundo aponta para o concretismo, que desponta depois na obra de Waldemar Cordeiro. Em Abaporu, Tarsila traz no título a referência indígena-brasileira, pois Abaporu significa em tupi-guarani canibal. A vegetação dos cactos é forte como o nosso homem nordestino, popular e rural, aguenta a tudo. De inspiração surrealista e fantástica, Tarsila, antropofagicamente, cria uma obra brasileira. Em outras fases de sua obra, Tarsila aborda a paisagem brasileira, a religiosidade popular e o operariado paulistano, incorporando as cores azul e rosa à fase que chamava de caipira. A incorporação de elementos populares também aparecem nas obras de outros artistas do modernismo como Anita Malfatti, Di Cavalcanti, Portinari, Segall, Guignard, Volpi, Victor Brecheret e Vicente do Rego Monteiro. Di Cavalcanti pinta serestas, mulatas, sambistas, moleques, trabalhadores, favelas, casas pobres do interior rural. Anita Malfatti e Segall incorporam a figura do mulato e da mulata em suas obras, enfatizando os traços negróides de nossos mestiços. Portinari além da valorização do mulato, na sua fase em Brodósqui, pinta festas na praça, rodas infantis, jogos de futebol e na década de 40 volta-se para a arte com temas de preocupação social. As obras de Guignard e Volpi apresentam a paisagem das cidades brasileiras e investigam e propõem debates sobre a construção da identidade e do imaginário popular. Alfredo Volpi parte dos casarios populares e das bandeirinhas de festas juninas, buscando sintetizar estes elementos através de uma geometria cada vez mais depurada. Ligados à cultura indígena destacam-se as obras do escultor Victor Brecheret e do pintor Vicente do Rego Monteiro, em que elementos desta cultura são absorvidos genialmente.

O século XX foi marcado também por um crescente interesse pelos estudos acerca da expressão plástica dos doentes mentais, os quais proporcionaram mudanças no campo cien- 
tífico e artístico. Luiz Carlos Mello (2015) ressalta o trabalho de Nise da Silveira que criou o Museu de Imagens do Inconsciente, possibilitando ao público compreender o universo interior do esquizofrênico. Entre os artistas-pacientes que criaram obras incorporadas na coleção desta instituição destaca-seAdelina Gomes, Emygdio de Barros, Fernando Diniz, entre outros. Suas artes já foram expostas em grandes exposições nacional e internacional de arte. Ainda nesta esteira entre arte e loucura, entre erudito e popular, ressalta-se a obra de Arthur Bispo do Rosário que desenvolveu sua arte como uma missão divina. Um dia, na véspera do Natal, Bispo acreditou ter visto Cristo, neste encontro, ele afirmou ter recebido a missão de recriar o universo para apresentar a Deus no dia do Juízo Final (Lazaro, 2012). Bispo constrói em seu "atelier" improvisado na colônia Juliano Moreira, no Rio de Janeiro, já possuído por poderes de uma capa que contém o nome de todos os países do mundo, uma nova ordem de mundo assegurada simplesmente pelas imagens. Bispo foi internado jovem e através da força das imagens viveu, entre entradas e saídas, durante 50 anos na Colônia. Hoje, o conjunto de sua obra está reunido no Museu Bispo do Rosário. Realizou cerca de 800 obras, entre elas: estandartes, roupas, objetos, vitrines, entre outros. Suas assemblages e objetos eram cenários de sua estada na Terra, como um inventariante do mundo. O seu trabalho é o de um cartógrafo intuitivo a registrar sua passagem. Bordava seus mantos com linha azul desfiada do uniforme que vestia da Colônia. Sem nenhum parentesco com estilos ou movimentos pré-concebidos, Bispo soube construir um mundo próprio, uma linguagem própria, buscada nas forças mais secretas do ser. Sua obra tem referência a duas questões que se desenvolveram na arte contemporânea brasileira: o universo da cultura popular brasileira, a arte mestiça e a arte da assemblage. Bispo do Rosário mantinha a tradição de um poeta de cordel, em que se apropria do saber popular, contando histórias e tirando suas referências de temas das festas populares do interior, como a roda e o carrossel de cavalinhos. Estas referências, à cultura popular e à assemblage, podem ser vistas também na obra de artistas que pertencem ao circuito da arte contemporânea, como Hélio Oiticica, Nelson Leirner, Glauco Rodrigues, Jarbas Lopes e Marcos Cardoso. Hélio Oiticicacriou entre outras obras, o Parangolé, que ele chamava de "antiarte por excelência”, uma pintura viva e ambulante. O Parangolé é uma espécie de capa (bandeira, estandarte ou tenda) que só com o movimento de quem o veste revela plenamente suas cores, formas, texturas e textos, com mensagens como "Incorporo a Revolta" e "Estou Possuído". Em 1965, ao apresentar os Parangolés vestidos por passistas da Mangueira na mostra Opinião 65, foi expulso do MAM do Rio de Janeiro, evento que acentuou seu interesse em desenvolver uma arte inseparável de questões sociais, rompendo com a fronteira entre arte erudita e popular. Oiticica viveu na Mangueira, tornou-se passista da Estação Primeira e elegeu o morro como lugar de muitas manifestações. Na conexão entre o coletivo e o individual, dá-se o interesse pela primitividade construtiva popular. Conduru (2007, p. 83) escreve que "Os outros" para Oiticica tem nome, Mosquito, Cara de Cavalo, Nildo, Magnólia, afirmando assim a relação com o samba e a cultura afro-brasileira.

Usando e abusando da confluência dos meios da cultura de massa e linguagens artísticas, a instalação Tropicália de Hélio Oiticica misturava o erudito e o popular. A obra fazia a síntese da arte construtiva com o experimentalismo, juntando em um só ambiente, o rigor geométrico com o caos da arquitetura das favelas, o controle e a improvisação, a ordem e o desequilíbrio, os ícones brasileiros e o internacionalismo, o bom e o mau gosto, além de 
papagaios, palmeiras, pintura e televisão. É neste sentido, no que se refere ao processo de hibridação cultural, que a obra de Oiticica e dos artistas citados da história da arte brasileira dialogam com as obras mestiças de Jarbas Lopes e Marcos Cardoso

\section{Arte mestiça de Jarbas Lopes}

Neste caminho, nos anos 90, a obra de Jarbas Lopes rompe com qualquer fronteira entre popular e erudito. Jarbas Lopes, nascido em Nova Iguaçu, em 1964, atualmente reside em Maricá, no Estado do Rio de Janeiro. O artista trabalha em uma oficina que é uma habitação de pau-a-pique projetada por ele mesmo no terreno de sua casa. Jarbas é bacharel em Escultura, formado pela Escola de Belas Artes da Faculdade Federal do Rio de Janeiro, em 1991.

O artista reflete sobre a experiência contemporânea individual e coletiva, as complexas relações entre os seres humanos, os produtos por eles criados e as forças poderosas e passivas da sociedade. Neste sentido, uma das características das obras de Jarbas é o cuidado com o meio ambiente através da reciclagem de produtos rejeitados. Jarbas recupera e reconfigura potenciais sobras de elementos de uso cotidiano: sacos plásticos, bucha, papel, fios de linha, latas, cartazes de rua, materiais de construção, entre outras coisas que vêm a formar seu repertório material. As investigações de Jarbas com diversos materiais em múltiplos contextos resistem ao materialismo capitalista não por meio de críticas inertes levantadas contra esse sistema, mas pela descoberta de uma qualidade transformadora e criativa em todo o seu material rejeitado. A obra de Jarbas revela um mundo cotidiano simples, popular, percebido por um catador contemporâneo (Chagastelles, 2012).

Uma das suas obras, Desembola/embola é uma proposição em que o espectador vivencia a arte, movimentando tufos de linhas coloridas que recebe em uma caixa. $\mathrm{O}$ fruidor resgata um emaranhado de sensações táteis, olfativas e visuais. Junto com as caixas são colocados dois defumadores que permanecem no espaço da proposição. A defumação vincula-se a elementos culturais afro-brasileiros ritualísticos, como os da Umbanda. O objeto Desembola/embola constitui-se de linhas variadas, multicoloridas e emboladas pelo próprio artista. O tufo de linhas é impregnado com odores diversos através de folhas vegetais que são colocadas na caixa com as linhas. Este tufo de linhas é inserido em uma pequena caixa de papel, também contendo frases escritas sobre um pedaço de papel para estimular o pensamento do fruidor, como, por exemplo: Cuidado com o outro; O besta conquistou a besta; Quanto mais me aborreço, mais fico feliz; A natureza é sabiá; entre outras. Além destas frases, nestas caixas são colocados também pequenos gravetos que são sugeridos para servirem como carretéis para possível organização das linhas desemboladas. Assim, as linhas desemboladas podem ser utilizadas na elaboração de um novo emaranhado, recriando o objeto. Evidenciam-se a reversibilidade da criação e os movimentos do homem: construir e destruir. Trata-se de um ciclo complementar, em que, no auge de um movimento, há a semente de seu oposto. 

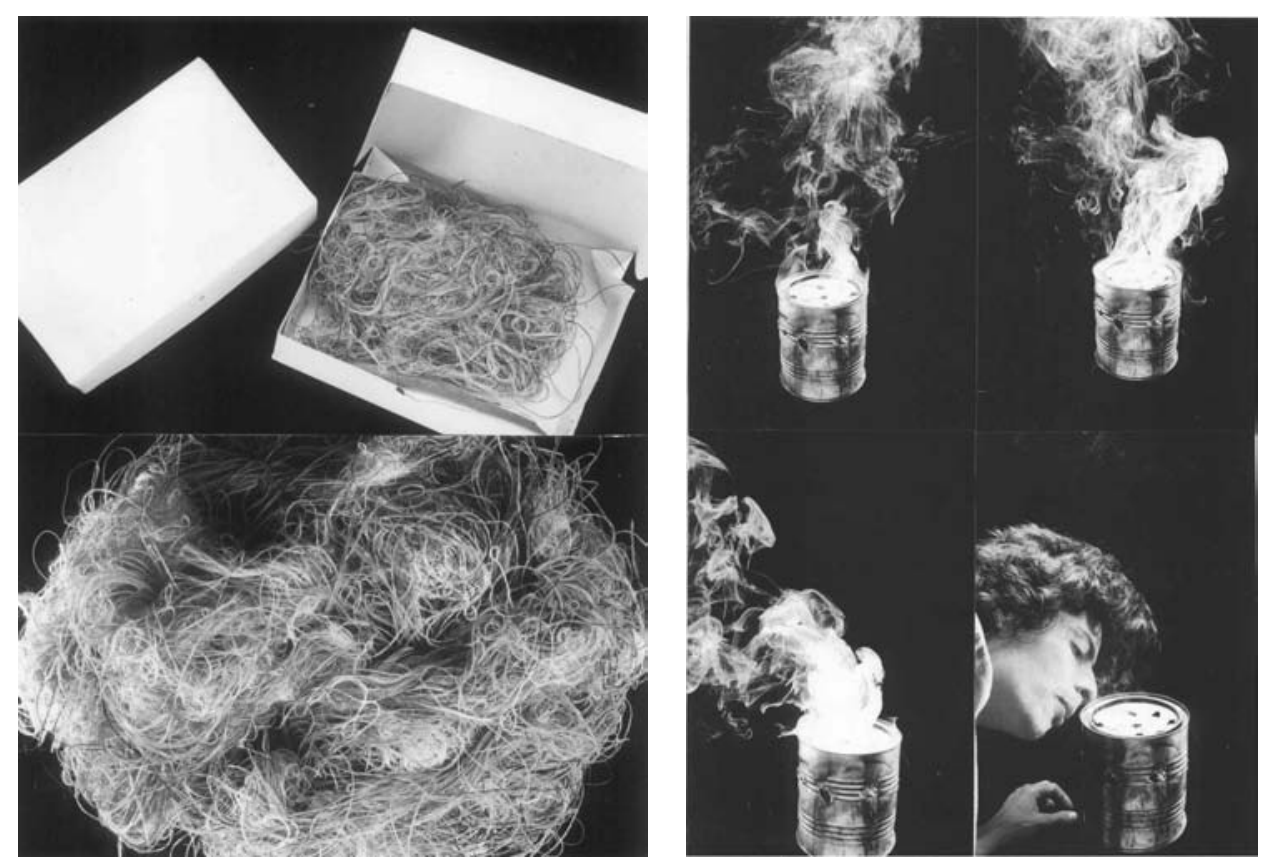

Figuras 1 e 2. Jarbas Lopes, Desembola/embola. São Paulo: Galeria André Viana, 2003. Acervo do artista.

Em Desembola/embola os fruidores brincam, constroem com humor, através da intuição e não da razão, o seu véu/texto, a sua trama, o entrelaçamento entre arte e vida. Em Desembola/embola, com cheiro, medidas e cores variadas, as linhas representam a aventura de cada um ao desembolá-las. Os sentidos se ampliam, desenvolvendo o ato de perceber e de sentir. Trata-se de uma experiência participativa, que abre espaço para compreensões estéticas e pessoais.

Em cada experiência é distribuída uma caixa para cada fruidor realizar a atividade. Junto com as caixas são colocados dois defumadores que permanecem no espaço da proposição, para manter o cheiro do ambiente. Jarbas queima misturas vegetais, adquiridas de cascas especializadas e elaboradas a partir de preparados próprios. Os defumadores são realizados em latas recicladas e, para segurança, devem permanecer em cima de um tijolo.

A defumação é a queima ritualística de certas ervas ou essências sólidas e tem como objetivo purificar o ambiente, diluindo os fluidos pesados e o mau-olhado. Ela vincula-se a elementos culturais afro-brasileiros ritualísticos, como os da Umbanda ${ }^{1}$. Para Mircea Eliade (1992), todos estes atos que possuem significado definido de algum modo participam do sagrado e tornam-se um ritual. O valor mágico de algumas ervas, também se deve a 
um protótipo celestial da planta, ou ao fato de que o primeiro a colhê-la ter sido um deus ${ }^{2}$. Nenhuma planta tem valor precioso em si mesmo, mas apenas por intermédio de sua participação em um arquétipo, ou pela repetição de determinados gestos e palavras que, isolando-os do plano profano, levam à sua consagração.

Espada de São Jorge, Palma de Ramos, Quebra Tudo, Levante, Guiné, Arruda Macho, Arruda Fêmea são alguns exemplos de plantas mais frequentemente usadas no ritual da defumação. Assim, através do olfato, os fruidores captam aromas que favorecem a atualização de lembranças do passado. Através dos aromas os fruidores podem permanecer relaxados, pois a defumação harmoniza o ambiente, proporcionando uma vibração contagiante em que, segundo Jarbas Lopes, opera-se a elevação dos sentidos com esses elementos usados na cultura afro-brasileira.

A referência à cultura afro-brasileira também aparece em sua obra "Bucha", neste ambiente o participante encontra-se envolvido por uma estrutura crua feita de fibra vegetal, em que são costurados cravo e canela. O participante é convidado a se despir para manter um contato íntimo da pele com a bucha áspera. A imagem deste ambiente remete ao Orixá Omolu, que corresponde a São Lázaro na Igreja Católica.

Bucha: ambiente curto, Figuras 3 e 4, foi criado em 1998, por ocasião do projeto A imagem do som, realizado no Rio de Janeiro, com curadoria de Felipe Taborda. Para o projeto, foram convidados 80 artistas que deveriam desenvolver uma obra baseada em uma das músicas de um cantor brasileiro. O cantor destinado a Jarbas Lopes foi Caetano Veloso e a música respectiva, Janelas abertas $n^{\circ} 2$. Neste ambiente o participante encontra-se envolvido por uma estrutura crua feita de fibra vegetal, em que são costurados cravo e canela. $\mathrm{O}$ participante é convidado a se despir para manter um contato íntimo da pele com a bucha áspera. Ao entrar no casulo, o participante pode ver o lado de fora, surgindo uma sensação esquisita da total visibilidade que o fruidor encasulado tem do exterior, embora ele não possa ser visto. Neste sentido, o humor está presente nessa obra, pois todos em volta acham graça daquela figura bizarra que anda como uma espiga de milho pelo museu. Mas, por outro lado, o fruidor ali dentro, encontra-se em um estado livre e sua percepção de si mesmo é desenvolvida através desta vivência. Opera-se o desejo de uma transformação do fruidor, e isto é proposto através desta atividade humorada e extrovertida.

Sensibilizar o outro é claramente a intenção de Jarbas nesta obra. Na elaboração cuidadosa do ambiente, a estimulação é direcionada e os efeitos procurados, proporcionando uma experimentação variada. É evidente o empenho em dar um tratamento plástico à criação pelo rigor da concepção e feitura, sendo o elemento humano tratado como componente integrado à obra. A bucha desvestida pode ser apreciada por sua qualidade formal, mas está desinvestida de sua função básica: cobrir, abrigar o homem e mediar sua relação com o ambiente. Jarbas trabalha a perda da identidade da obra de arte como objeto autônomo. O material serve à fantasia do fruidor, que redescobre a possibilidade de criar novas formas e novas significações a partir deste recurso pobre (bucha vegetal), figurando seu imaginário. 

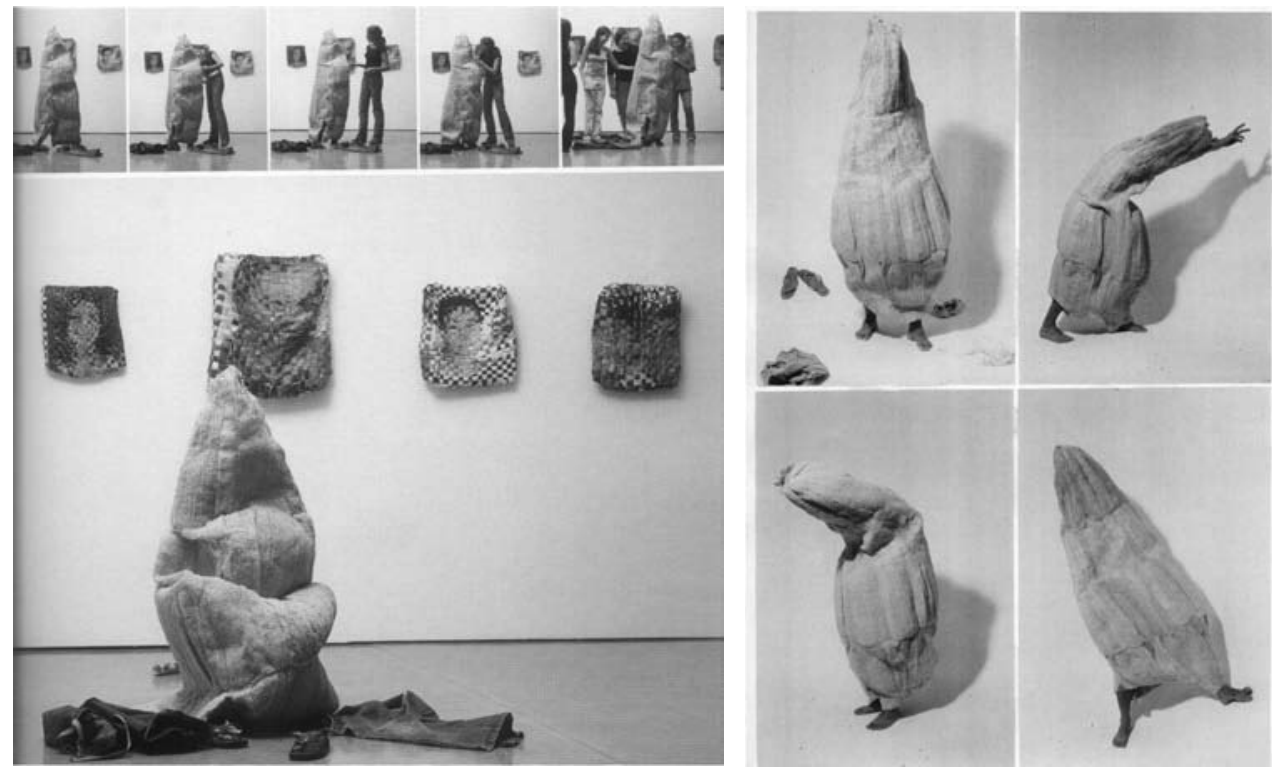

Figura 3. Jarbas Lopes, Bucha, Ambiente Curto. Rio de Janeiro, Paço Imperial na mostra A imagem do som de Caetano Veloso, 1998. Acervo do artista. Figura 4. Jarbas Lopes, Bucha, Ambiente Curto. Rio de Janeiro, Paço Imperial na mostra A imagem do som de Caetano Veloso, 1998. Acervo do artista.

Para realizar sua outra obra, a Barraca Deegraça, Jarbas recolhe o material do lixo urbano, como as faixas de propaganda política e de bailes funk populares realizados na Baixada Fluminense. O artista constrói uma casa móvel com estas faixas de plástico recolhidas nas ruas. Ao costurá-las, ele trança o mundo que o envolve. O artista chama de oca urbana esta barraca formada por plantas vivas, cores, letras, números e palavras que perdem a intenção inicial para assumir um discurso no sentido da beleza e da poesia. Jarbas faz referência ao profeta Gentileza ${ }^{3}$, personagem surgido do povo que pregou por todo o Brasil a fé na natureza, na beleza e na palavra. Os dois es de Deegraça são uma homenagem ao profeta, pois ele usava letras repetidas para enfatizar significados específicos. O princípio norteador da barraca é a gentileza, como modo de ser. Tanto Gentileza quanto Jarbas se voltam para um sentido de humanização da vida na cidade contemporânea. 

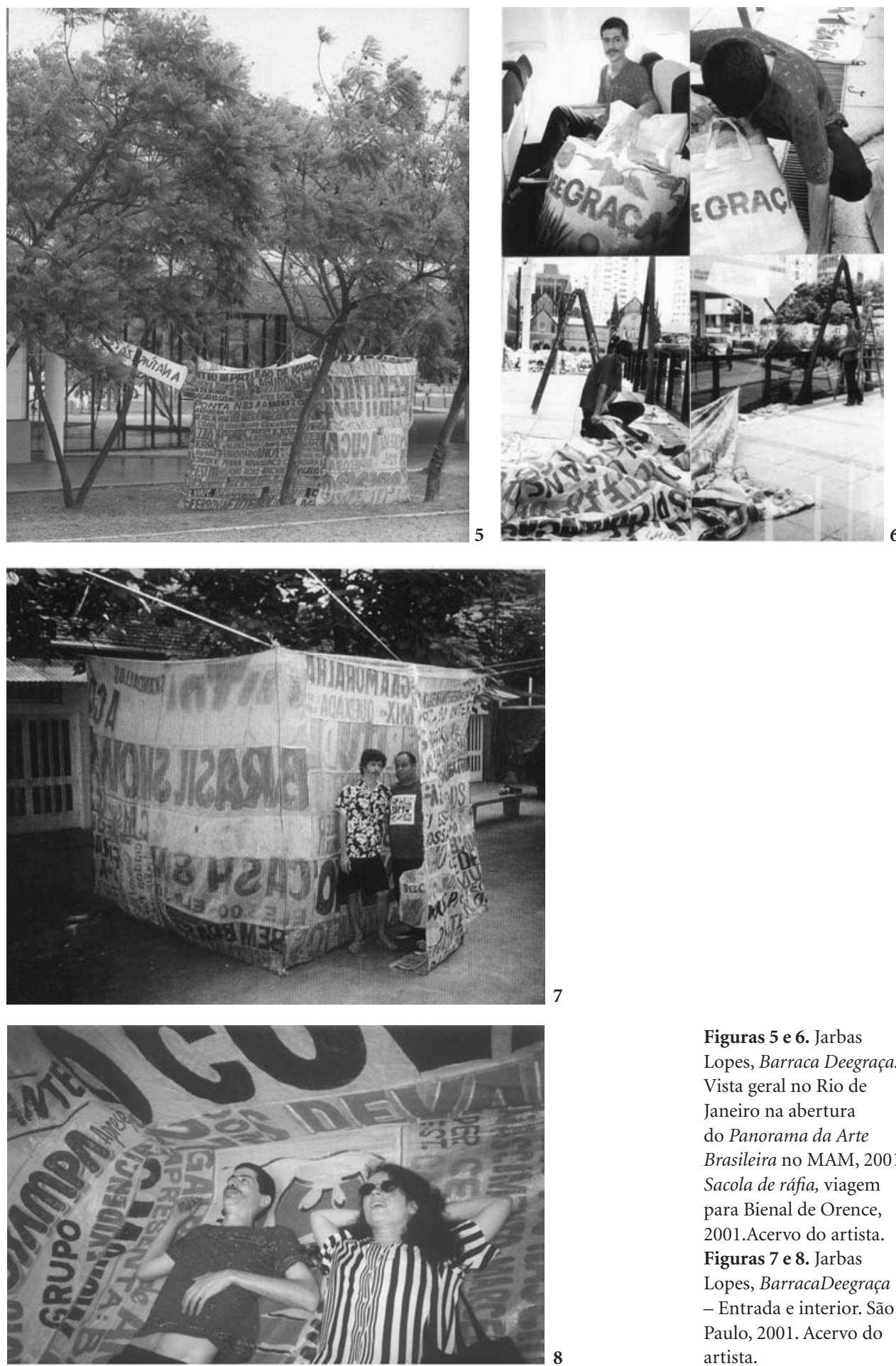

Figuras 5 e 6. Jarbas Lopes, Barraca Deegraça. Vista geral no Rio de Janeiro na abertura do Panorama da Arte Brasileira no MAM, 2001. Sacola de ráfia, viagem para Bienal de Orence, 2001.Acervo do artista. Figuras 7 e 8. Jarbas Lopes, BarracaDeegraça - Entrada e interior. São Paulo, 2001. Acervo do artista. 
As obras de Jarbas desafiam o espaço físico e ideológico. Para o transporte, suas instalações são dobradas e comprimidas dentro de uma sacola, dispensando custos de traslado, embalagem e seguro, uma vez que o artista as carrega pessoalmente até as exposições. Assim, esta obra é facilmente transportável e economicamente subversiva, pois Jarbas a carrega dentro de uma sacola de ráfia identificada com a inscrição Deegraça. Portanto, uma das graças da barraca é a simplicidade em poder se locomover e montá-la em qualquer espaço público, estando exposta à manifestação poética. A facilidade de locomoção possibilita que Jarbas monte a barraca frequentemente. Podemos citar alguns lugares por onde ela já foi esticada: no Centro Cultural São Paulo, em 1998; na exposição Panorama da arte brasileira, no MAM, em 2001; na Bienal de Orence, na Espanha, em 2001; e em vários outros lugares públicos, como nas ruas do Rio de Janeiro, de São Paulo e de Londres.

Artur Barrio e sua rejeição às forças dominantes intelectuais e materiais, que conduzem o mundo artístico, expressas no manifesto dos anos 1970 e materializadas em suas Situaçõesambientes, como em P.H. (Papel higiênico) e T.E. (Trouxas ensanguentadas), surgem como ponto de referência para Jarbas. A arte de Barrio destaca-se por ser contra as categorias de arte e contra a crítica de arte; assim, opera-se uma aproximação ideológica e artística entre Jarbas e Barrio, pois ambos são contra a burocracia e contra a mais-valia.

O artista chama de oca urbana esta barraca formada por plantas vivas, cores, letras, números e palavras que perdem a intenção inicial para assumir um discurso no sentido da beleza e da poesia, em que Deegraça é a palavra-chave que liberta o participante de qualquer outra intenção que não seja estar próximo do outro, da natureza e de dar e receber. Jarbas faz referência ao profeta Gentileza4, personagem surgido do povo que pregou por todo o Brasil a fé na natureza, na beleza e na palavra. Os dois es de Deegraça são uma homenagem ao profeta, pois ele usava letras repetidas para enfatizar significados específicos.

O princípio norteador da barraca é a gentileza, como modo de ser. Tanto Gentileza quanto Jarbas se voltam para um sentido de humanização da vida na cidade contemporânea. A cidade, marcada pela violência e pelo desapego de seus habitantes, coloca-se para Jarbas como um mundo a restituir. A faixa é o meio de divulgação barata que serve tanto para a luta contínua quanto para a propaganda das campanhas de candidatos políticos. Assim, Jarbas faz uma crítica à sociedade de consumo, construindo uma oca urbana, um espaço poético onde se possa celebrar a criação artística, o encontro entre as pessoas e consigo mesmo, pois para Jarbas a criação artística é fértil e vem De Graça, Com Graça, é Engraçada. O uso da arte gráfica, da palavra, de frases, sempre teve destaque na arte de Jarbas, como vimos em Desembola/embola, em que o artista utiliza palavras e poesia em sua estrutura, tais como: O Criador e Inflamável. Assim, na Barraca Deegraça, a ligação entre arte e poesia é enfatizada pela sua estrutura gráfica, pois são colocadas faixas com nome de lugares, data, nome de eventos, bem como faixas recolhidas nestes ambientes coletivos que anunciam frases populares como: Mulher até meia noite não paga; Arte para todos; Criança, charme dos milagres; Simplesmente, emoções restaurando vidas; O maior galerão: família, futebol, amigo, festa; entre outras.

Toda essa experiência em que desemboca essa obra, a própria problemática da liberdade, do dilatamento da percepção do indivíduo, confronta o condicionamento social a que o homem está submetido. A posição é, pois, revolucionária no sentido do comportamento. A arte não é, aqui, instrumento de domínio intelectual, já não poderá ser usada como algo 
supremo, inatingível, mas como uma emoção que é apreendida diretamente e que move o indivíduo do seu condicionamento opressivo, estimulando que o fruidor faça novos agenciamentos. Assim, o que está em jogo é a invenção, pois esta enfatiza os processos, explorando o movimento perpétuo da vida como manifestação criadora. Os fruidores podem participar da montagem da obra, levar objetos pessoais para dentro da barraca, inventar e propor atividades, ou seja, fazer parte do processo de construção da obra. Em Barraca Deegraça efetua-se a poética do gesto, um modo de manifestação da vivência que designa ações, que se desenvolvem na barraca (um lugar aberto à participação de todos) proposta como espaço para transformações e vivências. Na Barraca, as pessoas podem se deitar, cantar, experimentar sensações e descobrir modos de viver, de estar no mundo. É um ambiente comunitário, um campus experimental, uma espécie de taba, onde todas as experiências humanas são permitidas. É um lugar mítico para as sensações, para as ações, por isso proposições abertas são dadas e até materiais brutos e naturais para fazer coisas que o participante será capaz de realizar.

Esta obra articula estrutura e comportamento sem que a sua concepção seja aprisionada pelas delimitações de galerias e museus. Assim, a Barraca Deegraça remete a Babylonests (1971), Ninhos (1970) e Whitechapel Experience (1969), obras em que Oiticica manifesta o desejo de não fazer exposição, mas de criar um acontecimento, um recinto-participação. Neste sentido, tanto no Édem quanto na Barraca Deegraça, o fruidor entra num campo de ações desconhecido que lhe desperta os sentidos e atualiza as suas memórias, estimulando-o, assim, a agenciar novas relações e a se recriar. Na Barraca Deegraça, portanto, opera-se um espaço aberto a vivências, à produção de novos sentidos. Esta barraca é uma estrutura realizada com faixas do lixo urbano que Jarbas como um catador contemporâneo recolheu das ruas. A obra de Lopes, elaborada a partir de elementos populares recolhidos da rua, dialoga com as vestes realizadas de guimbas de cigarro de Marcos Cardoso.

\section{Arte mestiça de Marcos Cardoso}

Marcos Cardoso nasceu na cidade de Paraty, no Rio de Janeiro, em 1960. Graduou-se em Educação Artística na Escola de Belas Artes da Universidade Federal do Rio de Janeiro, em 1992. Frequentou o Ateliê de Gravura da Escola de Artes Visuais do Parque Lage e a Oficina de Gravura do Ingá, de 1988 a 1990. Marcos trabalha para o Carnaval Carioca tanto com criação, execução e coordenação de pinturas e esculturas quanto com o desenvolvimento de enredos. É também cenógrafo de televisão, eventos de moda e de cinema. Marcos Cardoso, assim como Bispo do Rosario e Jarbas Lopes, é um catador contemporâneo. Coleta elementos descartados, jogados fora, como guimbas de cigarro, reciclando em arte. Marcos realiza obras com guimbas de cigarro que recolhe nas ruas. Este ato beira a mendicância, pois muitas vezes é confundido com os mendigos nas suas andanças aleatórias para catar no chão o resto do resto: guimbas. Após a coleta, constrói objetos como "Redes de pescador", "Corações", "Totens" e "Vestidos" dando uma nova ordem aos resíduos do fumo contido nestes pequenos objetos do vício. $\mathrm{O}$ artista recicla ervas em sonhos que exalam perfumes que remetem a uma sensação de encantamento e nojo. A arte para 
Marcos solapa os limites cada vez mais questionáveis entre a arte popular e a arte considerada erudita. Marcos promove um dos aspectos mais incisivos da arte contemporânea: a substituição dos materiais artísticos tradicionais como tinta à óleo e mármore por elementos banais como guimbas e resíduos.

O artista constrói em seu ateliê-casa em Maricá uma nova visão de mundo afirmada pela arte. Marcos Cardosoinicia o seu processo, em um passeio aleatório a cada manhã, em busca do achado no chão. Em seguida, o artista segue para o ateliê onde estrutura e dá ordem ao conjunto de guimbas. Do conjunto acumulado, o artista cola uma após a outra. Algumas com marca de bocas de batom vermelho como "Corações", outras encardidas e pisadas pelos transeuntes. Com estas guimbas Marcos Cardoso apresenta estruturas plásticas fisicamente frágeis, porém fortes no impacto alegórico (Chagastelles, 2013).

Defino a obra de Marcos como gênero de arte-objeto que, contrariamente àquele representado pelo Dada, não apresenta os objetos despidos de sua rede natural de relações, mas enfatiza a complexidade de seus vínculos com o mundo que os cerca, da memória e do esquecimento, provocando um permanente questionamento da realidade. Assim, como Jarbas e Bispo, são usados objetos triviais que Marcos se apropria experimentalmente dos elementos da cultura popular. Muito além da força visual, o cheiro faz parte da obra. Suas esculturas-construções enfatizam o processo manual e artesanal.

Além de guimbas Marcos trabalha também com plásticos e rótulos com mensagens de marketing, embalagens, garrafas, restos e resíduos urbanos, como as obras "Sem Título", Figuras 12 e 13. O artista se apropria da comunicação visual desses produtos e cria almofadinhas de plástico, centralizando os rótulos dos produtos dos sacos de supermercado empregados. O artista, costura, cola e dobra, trabalhando com a manipulação artesanal de objetos da indústria como parte essencial de seu processo construtivo, de sua expressão alegórica.

Os trabalhos de Marcos Cardoso testemunham uma tendência geral da geração 90 como o aparecimento e a deculturação da arte. Com esses elementos Marcos cria obras que apresentam reflexões poéticas sobre o diálogo do homem com a cidade. Desenvolve sua obra no Rio de Janeiro - uma das grandes cidades do Brasil- e se contrapõe a esse universo tecnológico e poluído através da reciclagem.

Diferente do minimalismo onde se deseja uma gestalt, uma visão imediata do todo, a arte de Marcos parece flexível, aconchegante e empírica, instintiva e subjetiva, lírica, poética, paradoxal, à imagem dos aspectos irracionais e incontroláveis da experiência vivida. Traduz uma atitude moral e uma posição crítica. Coloca um olhar crítico sobre a tecnologia, sobre o progresso, sobre a estandardização dos produtos, e finalmente dos comportamentos humanos.

Como os minimalistas, Marcos abandona a iconografia antropomórfica que governou as atividades esculturais anteriormente. Como os minimalistas ele escolhe se abrir a uma escala cenográfica, indispensável para a espécie de interação ou de confrontação direta entre obra e público. Mas Marcos procura suscitar a participação do espectador diferente do minimalismo. Ele pretende fazer sentir a dimensão alegórica da experiência humana. A obra de Marcos traduz uma marcha intuitiva. Ela exige uma suspensão dos mecanismos racionais a fim de solicitar a sensibilidade poética no sentido mais largo. Os elementos de sua obra não são desprovidos de uma história ou de uma dimensão temporal. Ao con- 

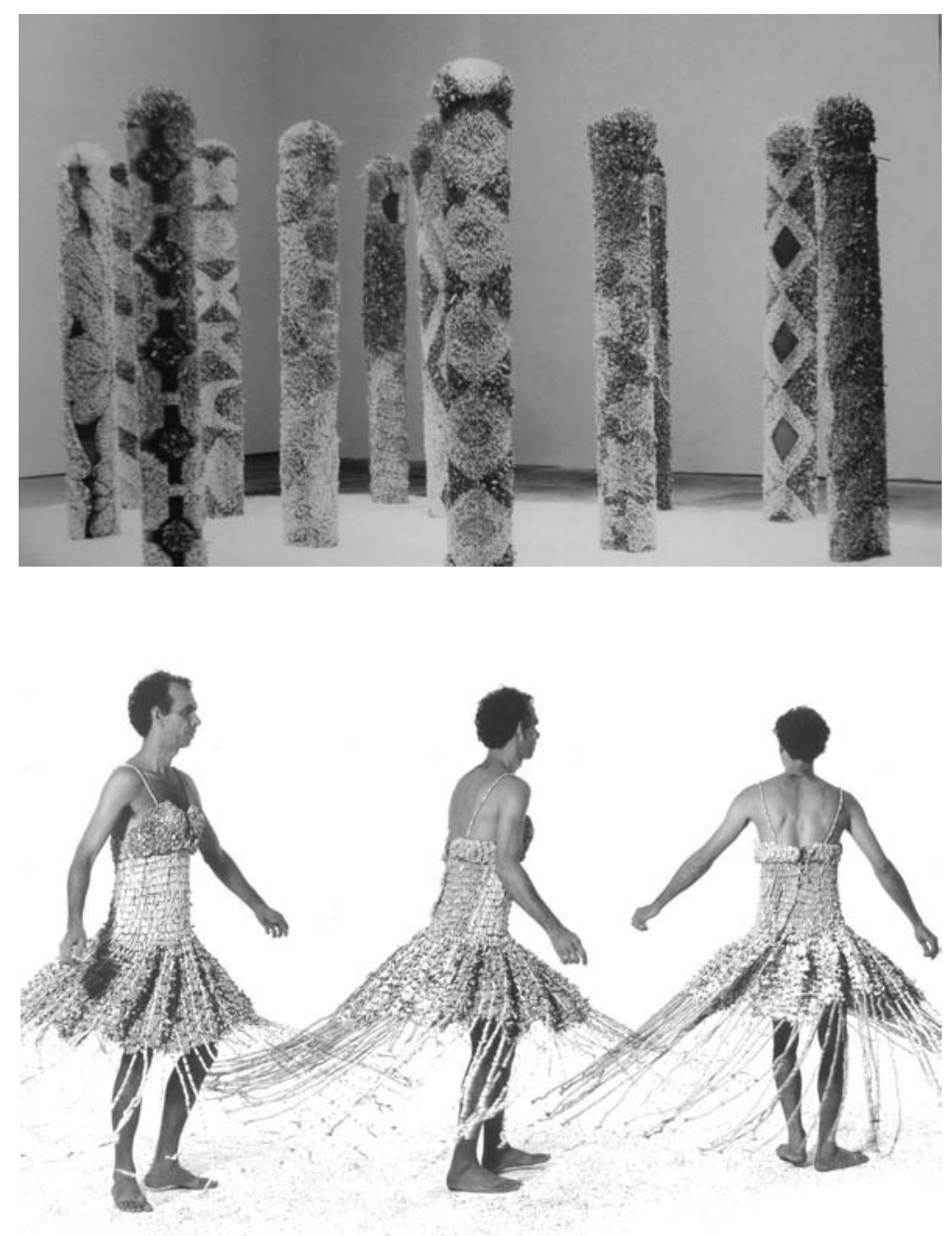

trário, eles carregam seus extratos sedimentários ao longo do tempo que constitui toda a experiência: do inconsciente coletivo, de uma subjetividade pessoal, de uma objetividade histórica e mesmo de realidades míticas em perpétuo retorno. Exprimem as estruturas temporais da razão, da intuição, dos gestos e dos atos. Enfim, designam as fases cíclicas das matérias orgânicas: crescimento, decomposição, movimentos, signos do tempo que passa. Assim, as formas concretas desses objetos e suas contradições internas provocam as sensações de uma complexidade perturbadora. A força de um cara a cara não se limita ao que o espectador percebe, mas intervém sobre lembranças instintivas, mesmo viscerais. Sua obra são tramas escultóricas em que os traços e as manifestações de energia, de tensão, de cheiro e de respiração suscitam outras. Nesta tensão, forma-se um ambiente alegórico, aberto e sem fim único. 

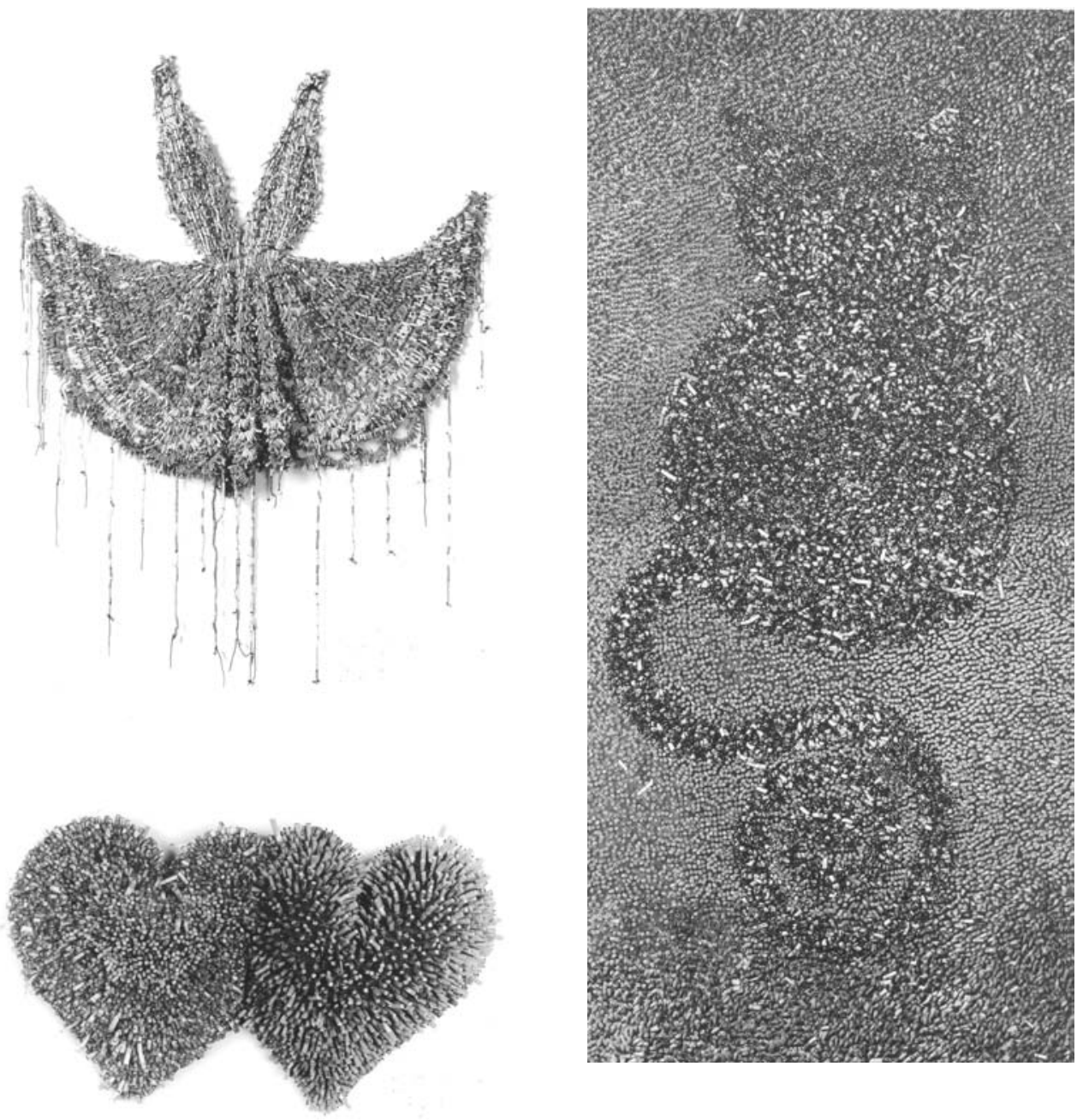

Figura 9. Marcos Cardoso, “Tótem I e II”, 1996-1999. (Guimbas de cigarro sobre PVC / 165 X 175 - 12 tótens de 30/40 cm cada) (Acervo do artista). Figura 10. Marcos Cardoso, "Série Tramas”, 1999. (Guimbas de cigarro e fios / $100 \mathrm{~cm}$ ) (Acervo do artista). Figura 11. Marcos Cardoso, "Série Tramas", 1999. (Guimbas de cigarro e fios / $100 \mathrm{~cm}$ ) (Acervo do artista). Figura 12. Marcos Cardoso, "Gato", 1996. (Guimbas de cigarro sobre isopor) (Acervo do artista). Figura 13. Marcos Cardoso, "Gato”, 1996. (Guimbas de cigarro sobre rede de pesca / 180 X 300 cm) (Acervo do artista). 


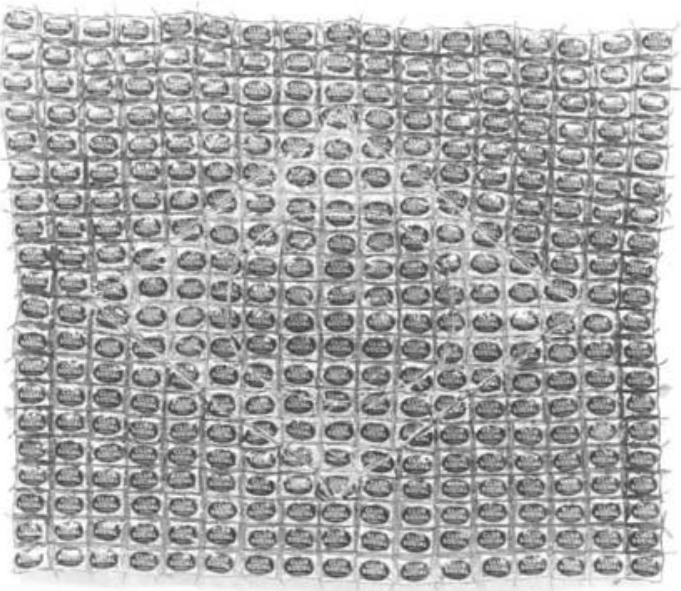

14

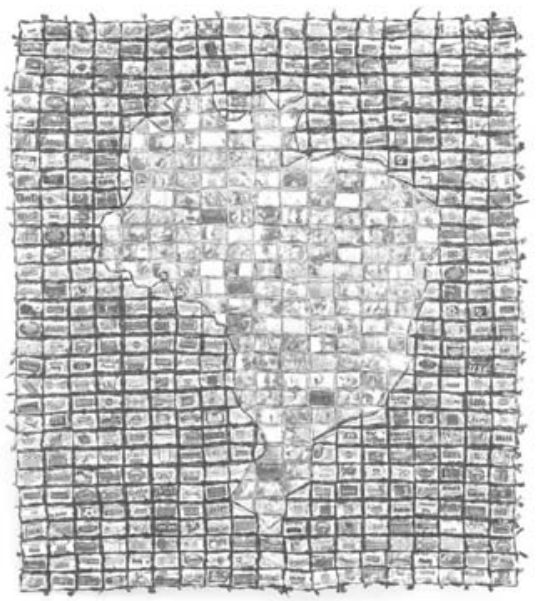

15

Figura 14. Marcos Cardoso,"Sem Título", 2002. (Rótulos costurados e recheados com plástico / 1,60 X 2,20 cm) (Acervo do artista). Figura 15. Marcos Cardoso, "Sem Título", 2002. (Rótulos costurados e recheados com plástico / 2,50 X 2,00 cm) (Acervo do artista).

\section{Considerações Finais}

Uma das características mais marcantes da obra desses artistas é a quebra de fronteira entre erudito e popular. Há uma multiplicidade de linguagens (performance, arte do corpo, instalação, poesia, ação, pintura), eles trabalham com um pouco de tudo. Os conceitos explorados também refletem a multiplicidade de escolha. O perfil da obra desses artistas começa a se delinear de forma mais clara diante de nós e a estabelecer, então, um plano de expressão de culturas híbridas. A visualidade de temas externos ao mundo da arte convive com as questões específicas do território artístico. Artistas explicitam as suas referências, muitas vezes provindas de domínios anteriormente considerados antitéticos. Lopes e Cardoso trazem à tonaas discussões acerca da arte efêmera, do material precário, do uso dos suportes não convencionais, como os matérias considerados lixo urbano, e o uso do corpo como obra.

Esses artistas refletem sobre a experiência contemporânea individual e coletiva, as complexas relações entre os seres humanos, os produtos por eles criados e as forças poderosas e passivas da sociedade. Neste sentido, uma das características das obras de Lopes e Cardoso é o cuidado com o meio ambiente através da reciclagem de produtos rejeitados. Eles recuperam e reconfiguram potenciais sobras de elementos de uso cotidiano: guimbas de cigarro, sacos plásticos, sacos de biscoitos, bucha, papel, fios de linha, latas, cartazes de rua, 
materiais de construção, entre outras coisas que vêm a formar seu repertório material. Como em iniciativas da economia alternativa, a ideia deles é reduzir as fases de produção, empacotamento e distribuição dos produtos industriais com o intuito de aumentar o custo/benefício, evitar o desperdício e cuidar da natureza.

As investigações de Lopes e Cardoso com diversos materiais em múltiplos contextos resistem ao materialismo capitalista não por meio de críticas inertes levantadas contra esse sistema, mas pela descoberta de uma qualidade transformadora e criativa em todo o seu material rejeitado. A obra desses artistas revela um mundo cotidiano simples, percebido por um inventariante contemporâneo. Seus trabalhos são orientados em direção ao valor do gesto arcaico e artesanal, como o de tecer e coser, uma ação simples, não espetacular, cotidiana. É uma maneira de recusar a competitividade e a eficácia da sociedade dominada pelo neoliberalismo, que provoca um estado de neurose.

A arte de Jarbas Lopes e Marcos Cardoso vem adentrando com força o circuito das artes eruditas da cidade, aceitas pelas academias, a crítica e o mercado de arte. Esta hibridação entre popular e erudito rompe com preconceitos como, aquele de que a melhor arte é a europeia; de que as Belas Artes (pintura, escultura e arquitetura) são mais importantes formas de arte; e de que há uma diferença hierárquica entre artesanato e arte.Lopes e Cardoso desenvolvem manifestações artísticas que não cabem no erudito ou no popular, que brotam de seus cruzamentos ou em suas margens, a arte mestiça.

\section{Notas}

1. A defumação é um ritual milenar e se desenvolveu em várias culturas e religiões, mas no Rio de Janeiro, sua realização, atualmente, é mais frequente nos rituais ligados a umbanda (religião afro-brasileira proveniente do Candomblé).

2. Na Umbanda, o Orixá (espécie de Santo) que realiza a defumação é Ogum (Orixá que corresponde a Santo Antônio na Igreja Católica).

3. Gentileza, José da Trino (1917-1996), era um ex-comerciante que deixou família e bens, após o incêndio de um circo em Niterói, em 1961, para seguir um chamado de Deus: tornar-se profeta, a fim de espalhar gentileza nos muros e nas pontes da cidade e do país. A nossa época caracteriza-se pelo estigma da falta de cuidado com o outro e pela perda da gentileza nas relações interpessoais e sociais. Neste contexto, o profeta pregou a gentileza como alternativa para a humanidade. Seu impacto nas camadas populares foi grande, a ponto de ser chamado Profeta Gentileza. A partir de 1980, Gentileza inaugurou uma fase de sua atividade profética. Inscreveu seus ensinamentos em 55 pilastras do viaduto do Caju, à entrada da cidade do Rio de Janeiro. Denunciava as ameaças que pesam sobre a natureza, produzidas, dizia, pelo capeta-capital. A alternativa a esse mundo acabado reside na vivência da gentileza e da atitude de agradecimento. Para expressar a gentileza usava o código que conhecia, a simbologia trinitária católica. Tudo era pensado e anunciado em nome do Pai, do Filho e do Espírito Santo. A tempo e contratempo anuncia sem se cansar: Gentileza gera Gentileza. Deus Pai é gentileza que gera o Filho por gentileza. Recusa-se a dizer muito obrigado, porque, como argumentava, ninguém é obrigado a nada, pois todos 
devemos ser gentis uns para com os outros e nos relacionarmos com amor. No lugar de muito obrigado devemos dizer agradecidos, em vez de por favor, devemos usar por gentileza, pois assim, dizia, nos religamos à Gentileza ou à Graça que é Deus, porquanto Ele criou tudo com gentileza e na plena gratuidade.

\section{Bibliografia}

Andrade, M. (1984). Aspectos das artes plásticas no Brasil. Belo Horizonte: Itatiaia, $3^{a}$ ed. Araújo, E. (2010). A mão afro-brasileira: significado da contribuição artística e histórica. São Paulo: Imprensa Oficial do Estado de São Paulo: Museu Afro Brasil.

Chagastelles, G. (2013). Alegoria na arte brasileira (1980- 2000). Rio de Janeiro: Multifoco. . (2012). Eternidade do efêmero: memória e vivência na arte brasileira de Jarbas Lopes, Laura Lima e Cabelo (1990-2000). Rio de Janeiro: Multifoco.

Conduru, R. (2007). Arte Afro-Brasileira. Belo Horizonte: C/Arte.

Duarte, P. (1998). Anos 60: transformações da arte no Brasil. Rio de Janeiro: Campos Gerais.

Eliade, M. (1992). Mito do eterno retorno. São Paulo: Mercuryo.

García Canclini, N. (2011). Culturas Híbridas: estratégias para entrar e sair da Modernidade. São Paulo: Editora da Universidade de São Paulo, v 1 e 2.

Lazaro, W. (Org.) (2012). Arthur Bispo do Rosário/ Emanoel Araújo... [et al.]. Rio de Janeiro: Réptil.

Mello, L. (2015). Nise da Silveira: caminhos de uma psiquiatria rebelde. Rio de Janeiro: Automatica: Hólos Consultores Associados.

Oliveira, M. (Org.). (2002). O Aleijadinho e sua oficina: catálogo das esculturas devocionais. São Paulo: Capivara.

Zilio, C. (1982). A Querela do Brasil - A questão da identidade na arte brasileira: a obra de Tarsila do Amaral, Di Cavalcanti e Portinari/ 1922- 1945. Rio de Janeiro: Funarte.

Resumen: El presente artículo trata del arte hecho por los artistas contemporáneos brasileños Jarbas Lopes y Marcos Cardoso, entre los años 1990 y 2010. En esas obras ellos presentan culturas híbridas, rompiendo con la diferencia jerárquica entre artesanía y arte, yendo al encuentro de las nociones de arte mestiza, especialmente a partir del concepto formulado por Néstor García Canclini. Se discute, de este modo, el ambiente del arte y de la existencia del hombre en su cotidiano y las formas de control del espacio y del cuerpo del sujeto, así como las estrategias de resistencia a través de la búsqueda del rompimiento de fronteras entre erudito y popular.

Palabras clave: Arte mestiza - Culturas híbridas - Arte contemporáneo brasileño - Jarbas Lopes - Marcos Cardoso. 
Abstract: The article deals with the mestizo art created by the Brazilian contemporary artists Jarbas Lopes and Marcos Cardoso, between the years 1990 and 2010. In these works they present hybrid cultures, breaking with the hierarchical difference between crafts and art, meeting the notions of mestizo art, especially based on the concept formulated by Néstor García Canclini. It goes about the environment of the art, the man in his daily life and the ways of controlling the man's space and body, as well as the strategies of resistance through the search for breaking of boundaries between scholar and popular.

Keywords: Hybrid art - Hybrid cultures - Contemporary brazilian art - Jarbas Lopes Marcos Cardos.

[Las traducciones de los abstracts fueron supervisadas por el autor de cada artículo] 